\title{
The Role of Metaphor, Metonymy, and Conceptual Blending in Understanding Advertisements: The Case of Drug-prevention Ads ${ }^{1}$
}

\author{
Javier Herrero Ruiz \\ University of La Rioja \\ javier.herrero@dfm.unirioja.es
}

\begin{abstract}
Over the last years, there has been a growing interest in the analysis of advertisements from the point of view of pragmatic theory (cf. Brierley, 1995; Myers, 1994; Rein, 1982; Tanaka, 1994). Nevertheless, pragmatic studies of the language of advertising from a cognitive perspective are scarce (cf. Turner \& Fauconnier, 2000; Coulson, 2000; Sánchez \& Gómez, 2002). In this connection, the aim of this study is twofold: first, we attempt to provide additional evidence about the role of metaphor, metonymy, and conceptual blending in the proper understanding of a set of drug-prevention ads and, second, we shall demonstrate that, in addition to determining the semantics of the slogans, the underlying mappings also constrain the choice of their related visual layouts; thus, the overall communicative effects brought about by the advertisement are further reinforced.

With this purpose in mind, we have drawn a corpus of sixteen drug-prevention advertisements, both in Spanish and English, which include slogans and images. The adverts under consideration have been entirely retrieved from the net, and contain expressions such as "keep your eyes open," "there is a long life ahead," or "turn away from drugs." We shall show that the interpretation of such examples ultimately exploits metaphor (e.g. FUTURE TIME IS IN FRONT OF EGO, KNOWING IS SEEING) and metonymy (e.g. EFFECT FOR CAUSE), either independently or in interaction, and conceptual blending.
\end{abstract}




\section{Introduction}

In this paper we attempt to show how conceptual metaphor, metonymy, and blending play a crucial role in the correct interpretation of advertisements as powerful mechanisms to convey the central idea that the advertisers want to convey. In this respect, the central idea is usually found within the inferential pattern that is drawn from a metaphorical, metonymic (either independently or in interaction), or conceptual blending process. Furthermore, these cognitive tools are essential in the visual structuring and layout of the adverts as regards characters and their traits, kinesics ${ }^{2}$ and proxemics ${ }^{3}$, etc.

In order to achieve our aims, we have analysed a corpus of sixteen drug-prevention advertisements in Spanish and English which include both slogans and images, and which can be explained on the basis of conceptual metaphor, metonymy, and conceptual blending. More specifically, we shall make use of Lakoff's standard theory of metaphor and metonymy (cf. Lakoff \& Johnson, 1980, 1999; Lakoff 1987, 1990, 1993; Johnson, 1987, 1992; Lakoff \& Turner, 1989; Langacker, 1987, 1990, 1991; etc.). Our analysis will also benefit from some of the proposals in Ruiz de Mendoza \& Díez (2002) where it is argued that conceptual interaction is fully regulated and constrained by a limited set of interactional patterns. Finally, we will complement our discussion with relevant insights from Turner \& Fauconnier's $(1994,1995,1996)$ theory of conceptual blending. As for the distinction between conceptual metaphor and blending, we shall apply blending theory whenever the source and target domains, which become the input spaces, have elements that correlate on the basis of the generic structure they share and which forms the generic space.

\section{Metaphor, metonymy, and conceptual blending}

Cognitive linguists have carried out a large quantity of studies on metaphor, an idealised cognitive model (or ICM) which results from performing a mapping across different conceptual domains. Traditionally, cognitive linguists have followed Lakoff \& Johnson (1980: 35-40) and Lakoff \& Turner (1989: 103-104) in their initial observations on the differences between metaphor and metonymy. In fact, their characteristics are very different:

(1) In metaphor there are two conceptual domains involved, one being understood in terms of the other, while metonymy only involves one conceptual domain, i.e. the mapping occurs within a single domain and not across domains.

(2) In metaphor, the source domain is mapped onto the target domain. In this process the source allows us to reason about the target. For example, in the metaphorical expression I have control over him we map height onto control thus conveying the idea that being in an upper position enables us to exercise control over other entities. In contrast, metonymy is mainly used for reference, since we can refer to an entity in a domain by referring to another entity in the same domain, e.g. Wall Street is in crisis 
(the street stands for the institution).

(3) The relationship between the source and target domains in metaphor is of the "is a" kind; in metonymy there is a "stand for" relationship, since one entity in a schema is taken to stand for another entity in the same domain or for the domain as a whole.

However, as Ruiz de Mendoza (1997a: 283) has noted, the only essential difference between metaphor and metonymy is related to the domain-internal and domain-external nature of the mapping, since both metaphor and metonymy can be used either referentially or predicatively. In this sense, The pig is waiting for his bill (the pig is the customer) and Wall Street is in crisis (the street stands for the institution) are examples of referential metaphor and metonymy respectively, whereas I have control over him (CONTROL IS UP) and $\mathrm{He}$ is a (real) brain (he is very intelligent) are instances of metaphor and metonymy used predicatively.

The "stand for" relationship is simply the result of the domain-internal nature of metonymic mappings; that is, the false impression that metonymies obligatorily require a "stand for" relationship derives from the fact that metonymies are constructed on the basis of a single conceptual domain, in such a way that one of the domains is already part of the other.

Ruiz de Mendoza (1997b: 169-171) claims for the existence of two types of metaphor from the point of view of the nature of the mapping process. Hence, we may find onecorrespondence metaphors (there is just one correspondence between the source and target domains; e.g. PEOPLE ARE ANIMALS, in which animal behaviour is mapped onto human behaviour) and many-correspondence metaphors (there are several correspondences between the source and target domains; e.g. LOVE IS A JOURNEY, in which the lovers are the travellers, the couple's shared goals are identified with the destination, etc.).
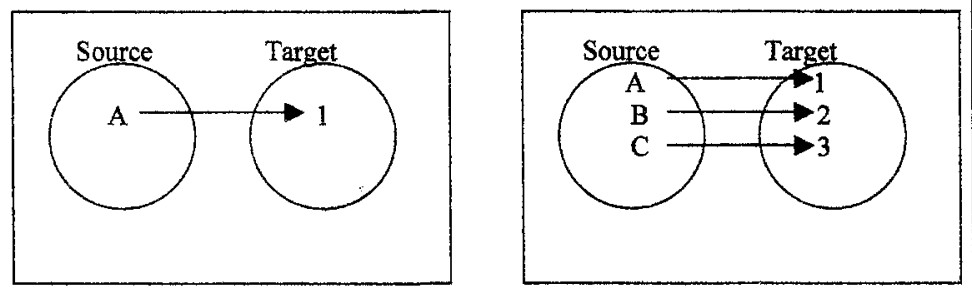

Figure 1. One-correspondence and many-correspondence metaphors.

Metonymies, which can be defined as instances of one-correspondence mappings, have been divided into target-in-source (the source domain stands for a target sub-domain) and source-in-target (a source sub-domain stands for a target domain) metonymies (Ruiz de Mendoza 2000; Ruiz de Mendoza \& Pérez 2001). 

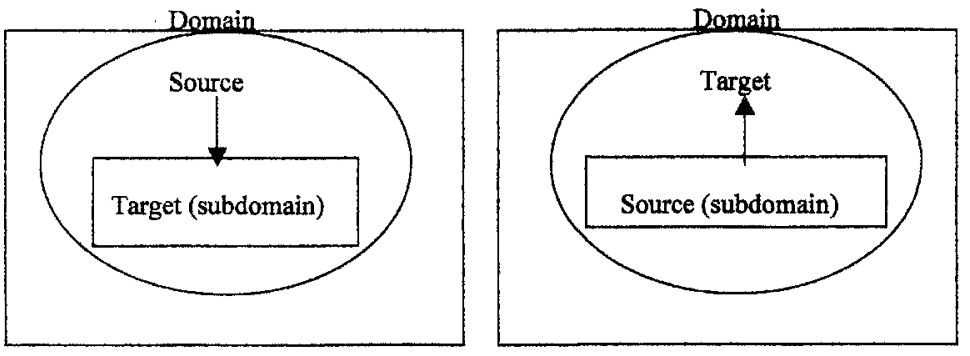

Figure 2. Target-in-source and source-in-target metonymies.
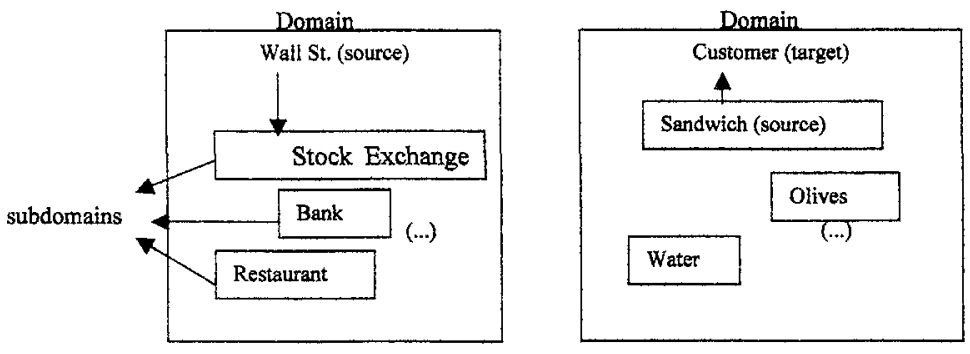

Figure 3. Examples of target-in-source and source-in-target metonymies.

Finally, metaphor and metonymy may interact in a number of ways that have been described in Ruiz de Mendoza \& Díez (2002) and Herrero (2002). We shall make use of this kind of analysis in order to address some of the issues arising from our study.

The notion of blending, which will also be useful for our analysis, has been presented as a refinement of Lakoff's two-domain model. It is part of a more general framework that has been developed by Turner \& Fauconnier $(1994,1995,1996)$ on the basis of the concept of "mental space", i.e. a relatively small conceptual structure built up for purposes of local understanding and reason (cf. Turner \& Fauconnier 1995: 184). In this approach ${ }^{4}$, whole domains are rarely, if ever, invoked when interpreting metaphorical expressions. According to Turner \& Fauconnier, a mental space generally retrieves data from more than one conceptual domain so that it creates its own structure, always smaller than that of the input domains. On the basis of this view, metaphor and analogy are the result of a blending process whose interpretation requires four mental spaces: two input spaces -a source and a target- and two middle spaces - a generic space and a blended space or blend. The structure from at least two input spaces is projected onto the blend (which integrates part of the structure from the input spaces into more complex events, thus becoming dynamic), while the generic space (which contains the basic structure of the input spaces) in turn licenses the projection (see figure 4). 


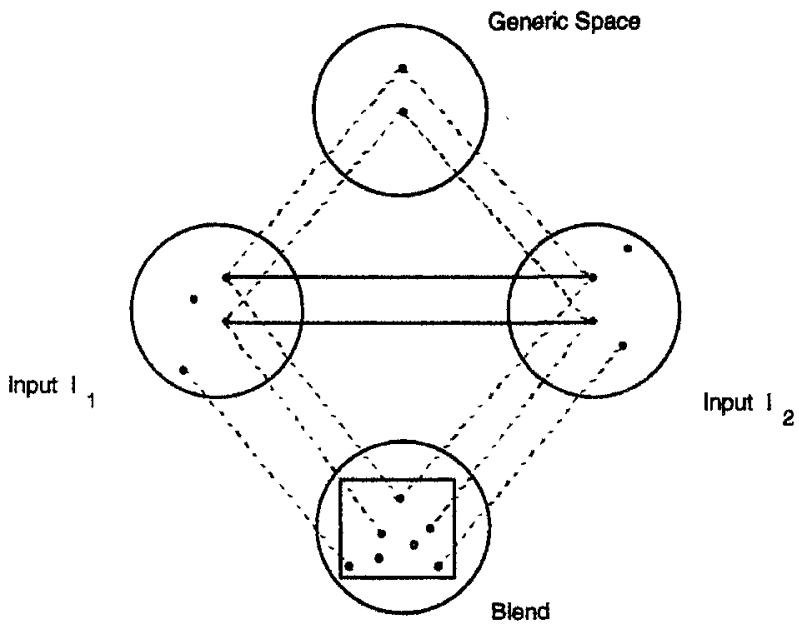

Figure 4. Schematic representation of conceptual blending.

This process is illustrated by the analysis of sentence His plan backfired on him in figure 5 below.

SOURCE

(Input space 1) A hunter intends to kill an animal. The hunter has everything prepared: rifle, lens, etc. The hunter makes out an animal in the distance and locates it with the rifle, being just about to kill it.

The hunter shoots. The rifle backfires: the shot goes out from the butt of the rifle towards the hunter.
GENERIC SPACE

TARGET

(Input space 2)

\begin{tabular}{|l|l|}
\hline \multicolumn{1}{|c|}{ Someone has a clear intention. } & $\begin{array}{l}\text { Someone intends to do } \\
\text { something. }\end{array}$ \\
\hline $\begin{array}{l}\text { All is prepared and planned in } \\
\text { advance. }\end{array}$ & He carefully plans what to do. \\
\hline The plan is to be carried out. & $\begin{array}{l}\text { He conscientiously prepares } \\
\text { everything to carry out the } \\
\text { plan, being just about to } \\
\text { perform it. }\end{array}$ \\
\hline $\begin{array}{l}\text { The carries out the plan. } \\
\text { The action is performed. } \\
\text { opposite effect. }\end{array}$ & $\begin{array}{l}\text { The plan fails and has the } \\
\text { reverse effect that was } \\
\text { expected. }\end{array}$ \\
\hline
\end{tabular}

\section{BLENDED SPACE}

Someone, intending to do something, thoroughly plans and prepares what steps to take but just when he is about to do it the plan fails, having the reverse effect that was expected.

Figure 5. His plan backfired on him.

\section{Analysis of the corpus}

We have chosen a corpus of sixteen advertisements and posters with slogans and images related to some campaigns of drug prevention which took place in the USA, Great Britain, 
and Spain. All the advertisements, posters, and examples have been entirely retrieved from the net.

\section{- TO TURN AWAY FROM SOMETHING}

In the first expression under analysis, To turn away from something (Sp. dar la espalda), the source of the metonymy is a subdomain of the target, which provides us with the main elements in order to build the metaphoric mapping (the output of the metonymic mapping is the input to the metaphor) while focusing on only one of the correspondences (i.e. a person ignores something, in this case drugs). This is not possible with metonymies where the source is not a subdomain of the target, as Ruiz de Mendoza \& Díez have noticed (2002). This example falls under the pattern "metonymic expansion of a metaphoric source", as illustrated in figures 6 and 7 :

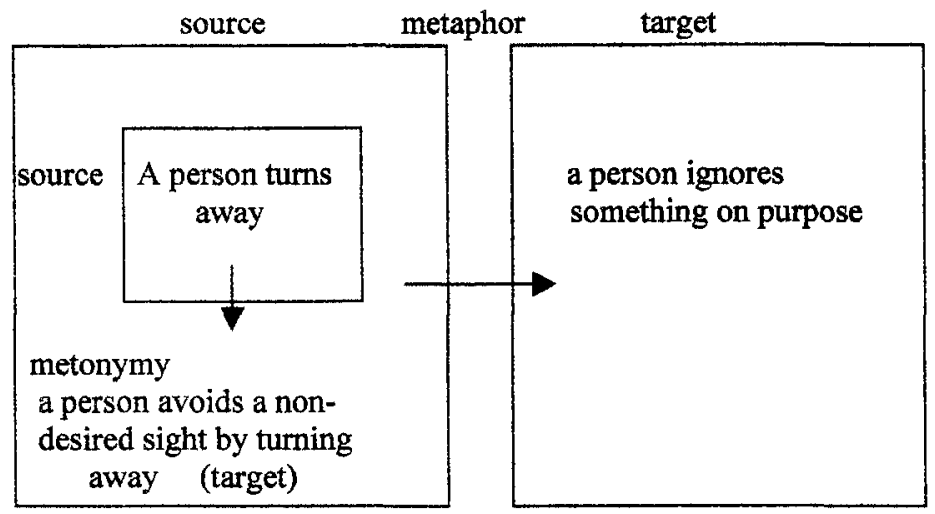

Figure 6. To turn away from something.

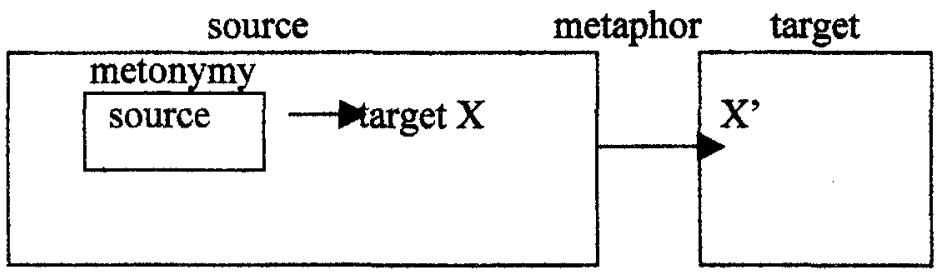

Figure 7. Metonymic expansion of a metaphoric source.

Regarding the design of the adverts, we obviously observe both a girl avoiding something (drugs and guns as inferred from the text) by turning away and, in the Spanish poster, the back of a swimmer together with the text Si quieres controlar las drogas dales la espalda (Eng. 'If you want to control drugs, turn away from them'). The Spanish 
campaign launched in 1996 was aimed at avoiding the extended idea that "it is possible to control drugs," by means of exploiting this expression, really common in the slang of young people, and by showing the contrast with sports that demand balance and control.

\section{- EATING IS DESTROYING}

This Spanish advertisement (under the name Porros y cocaina, Eng. 'joints and cocaine'), which was intended to avoid drug consumption, was based on a simile whereby a line of cocaine is seen as a worm that reaches one's brain and devours it completely. This simile is further supported by the slogan No metas las narices en la coca. Te hará polvo el cerebro (Don t poke your nose into cocaine. It will destroy your brain). Obviously, the image of the worm climbing into the nostrils and eating the brain leads to the metaphor EATING IS DESTROYING, which stems from the bodily experience based on eating, that is, destroying the food we put in our mouths so as to break it down into smaller fragments which, upon reaching the stomach, will be easily decomposed by its acids.

As usual, everyday language shows the pervasiveness of this metaphor, as may be seen in the examples below:

-I would like to reach any doctor in the SF area (I can't travel over about 7 miles) to help with this terrifying thing that is devouring me alive.

-My skin will burn, turn black for you, as the cancer eats me up, those strange eyes to see cry before I drop down to die, move your head up to mine so I can feel above you once more, Ineed to find there's someone below before I take that final fall (...).

-See kids, it's this type of conversation that proves to you that alcohol eats your brain.

In these examples eating is parallel to destroying, which may also be seen not only in the experience of eating but also in the fact that some animals eat something totally by destroying it, as is the case with woodworms regarding furniture.

\section{- THE BRAIN IS A SPONGE}

This Spanish advert entitled Habla con tu hijo (Talk to your son) shows, if we look carefully, that both the father and the child are speaking at the same time. In the real TV ad, both of them appear speaking at the very same time without actually reaching an agreement or even mutual understanding. This advert tries to make parents aware that they should discuss the issue of drugs with their children while keeping in mind that talking will not be effective if their children will not retain the ideas. This topic may be linked to the folk model that sees our brain as a sponge which absorbs words and ideas:

-If the brain is a sponge, why can't you remember half of what you did yesterday? The brain is not a sponge. It's a sieve.

-The brain absorbs information of which it is directly aware, but it also absorbs the unconscious signals that reveal our inner attitudes and beliefs.

This mapping consists of the following basic correspondences: the brain is a sponge, and 
information (in the form of images, words, ideas, etc.) is liquid that can be absorbed by the brain. Nevertheless, it may be also related to the idea that the brain is a container, whose entrance and exit are the ears, as the following sentences show:

-Unlock the ideas in your mind!

-To live life to the fullest, a person needs to fill his mind with as many ideas as possible.

-They often fly through the air with such overwhelming speed and variety that when you aren't sure what a particular expression means, it's possible that you may not have even noticed that the words have entered your ears.

-Whatever you tell him seems to go in one ear and out the other.

-Frankly there is no point in me explaining myself to him. Anything I tell him will go through one ear and out the other. It's like talking to a brick wall.

-(Spanish) Lo que te digo te entra por un oído y sale por el otro.

\section{- FUTURE TIME IS IN FRONT OF EGO}

The advertisement under analysis presents a girl called Raquel who says Hay mucha vida por delante (Eng. 'there is a long life ahead'). This expression can be explained on the basis of the conception of future time as being in front of the ego. More specifically, it makes use of an ego-based notion of time which, from an experiential point of view, stems from the fact that our eyes are in the front part of our bodies. At this point, the KNOWLEDGE IS VISION metaphor applies since, if we see time as a moving entity, what is known has already been seen and remains behind us; on the contrary, future things, as long as we move along the temporal path, are to be seen. In other words, areas behind a forwardfacing moving ego have been seen, while areas in front remain unseen and hence unknown (see figures below).

In this sense, we may distinguish two basic approaches to time (Sweetser and Nuñez, 2001). The so-called "ego-based," which is a deictic model that locates time in relationship to the human body; and the "relative" model of time, a non-deictic conception of time in which an event is located in relationship to another event within the temporal line. From this viewpoint, the ego-based model is the one which leads to the conception of time as being either in front of or behind the ego. Although there are some communities in which the norm does not apply (e.g. Aymara, as Sweetser and Nuñez, 2001, have shown), the conception of future time as being in front of the ego and of past time behind the ego is universal across languages. In this respect, Lakoff and Johnson (1999) have described the TIME-IS-MOTION metaphor in terms of the motion of an observer. The "location" of the observer is the present, the "space" in front of the observer is the future, and the "space" behind the observer is the past. "Objects" are events or times, "located" at various "points" along the "line". Nevertheless, the TIME-IS-MOTION metaphor may have two different interpretations: the observer can be thought of as moving forward at a constant speed, passing the events; or the events can be thought of as moving towards the observer. Lakoff and Johnson have additionally noted that we also map time onto the body image: in almost all languages, the observer "faces" the future although, as we mentioned before, a few languages (presumably noting that one can see the past, but not the future) have the 
observer facing the past. Regarding the second approach, from a "relative" conception of time we see that later events are in front of earlier events.

As Sweetser and Nuñez have shown, gesture is also quite telling of these conceptions of time. In fact, when talking about past events, we normally move our hands backwards whereas, if we refer to future events, we generally produce movements towards the front. To end with, the "relative" approach stems from the obvious fact that events are organised along a path in which earlier events are behind later events.

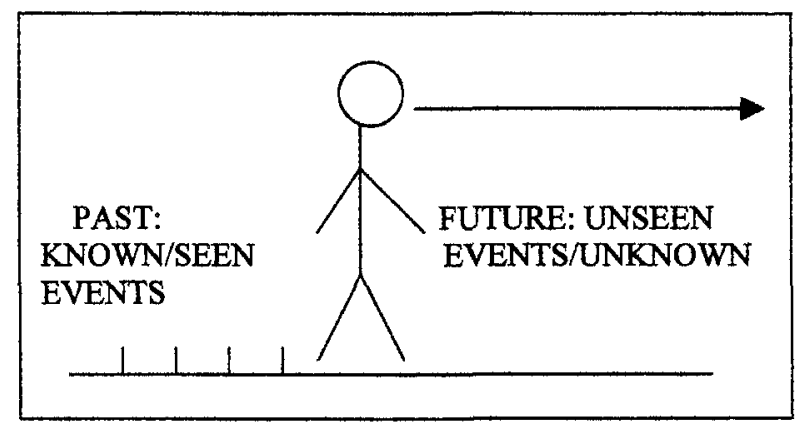

Figure $8^{5}$. Ego-based notion of time, person passing the events (e.g. future: We are coming up to the exam period, I don't know if I Il pass everything. E.g. past: We left the exam period, I passed everything).

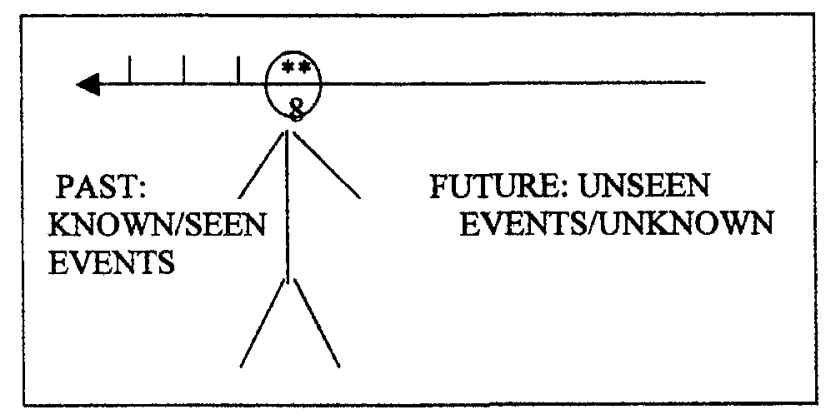

Figure 9 ${ }^{6}$. Ego-based notion of time, events moving towards the observer (e.g. future: The exam period will be coming soon, I don't know if I Il pass everything. E.g. past: The exam period has passed, and I passed all of my exams.).

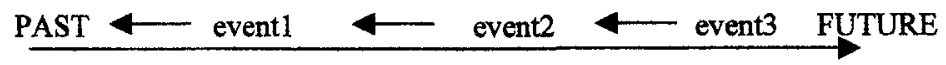

Figure 10. "Relative" notion of time. 


\section{KNOWING IS SEEING. BLIND IS ABSENCE OF KNOWLEDGE}

The KNOWING IS SEEING conceptual metaphor allows us to understand the abstract domain of knowledge by means of the concrete domain of sight. This is a metaphor with a clear experiential basis grounded in the fact that in early childhood human beings normally receive cognitive input while seeing. Nevertheless, whereas in the first years of one's life perception and cognition are conceived as together (or conflated in terms of Johnson), due to the fact that there is a deep basic correlation between the intellectual input and vision, afterwards these two domains separate from each other ("deconflation" in Johnson's words). This is the reason why we are able to use the metaphor KNOWING IS SEEING meaning just "awareness" with no actual link to vision at all, as may be seen in everyday language expressions like the following:

-I see what you're getting at.

-His claims aren't clear.

-The passage is opaque.

In the advertisement we are discussing we see that being blind to drugs stands for not being aware of the consequences. In this sense, being blind to drugs and their effects is really bad since you may not realise that they have a negative impact on you.

\section{- TO KEEP ONE'S EYES OPEN}

The following example, put forward by Ruiz de Mendoza \& Díez (2002), presents a central open eye surrounded by different sorts of drugs. From a linguistic point of view, this advert may be explained by the fact that the metonymy included, being one of the source-in-target type, has the main function of developing the source of the metaphor in order to interpret it correctly. Suffice it to say that the role of this type of metonymy is the same independently on whether it works on the source or on the target of the metaphoric mapping. In this poster, a person performs the action of "keeping his eyes open" in order not to close them. Then, the target of this metaphor maps onto a more general situation in which a person keeps his eyes open as the way to be alert against possible dangers or problems. So, there is a source-in-target metonymy with the main function of developing the target of the metaphoric mapping to get a full understanding of it (see figure 11 and 12).

A different although related interpretation of the whole issue may stem from the metaphor KNOWING IS SEEING. Since we see a central open eye surrounded by many different pills (which stand for the drugs), we may infer that the campaign tries to convey the idea that we should learn about drugs and their negative effects on us.

\section{THE GREAT CHAIN METAPHOR: PEOPLE ARE ANIMALS}

This funny poster shows a dog wearing human shoes, and it contains a slogan saying "Taking drugs is just as dumb". In American English slang, dumb means 'stupid', which obviously refers to the fact that if in life dogs do not need to take walks with shoes on, human people do not need to take drugs. Thus, if people take drugs, it is something stupid 
due to the fact that our bodies don't need them. This is made fully comprehensible to us on the basis of a mapping which finds its source domain in the image of the dog with human shoes seeming stupid, and with a target domain containing the image of a person who takes drugs seeming stupid too.

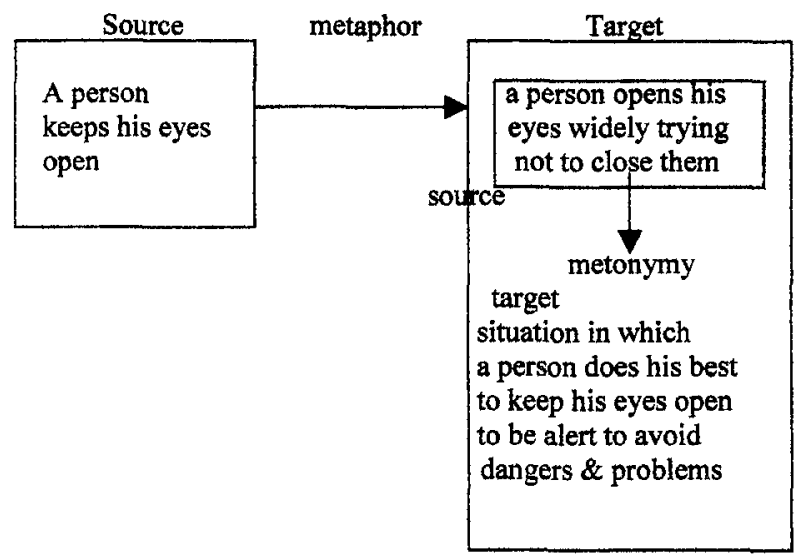

Figure 11. To keep one's eyes open.

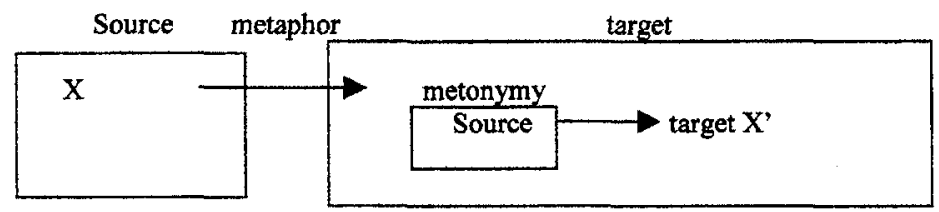

Figure 12. Metonymic expansion of a metaphoric target.

What seems to motivate this simple metaphor is the complex mapping PEOPLE ARE ANIMALS, which in turn derives from the GREAT CHAIN METAPHOR (cf. Lakoff \& Turner, 1989). The GREAT CHAIN METAPHOR allows us to understand non-human attributes in terms of human character traits. Under the name of the Great Chain of Being, we manage to treat ontological metaphors as an exploitation of a folk model in which different kinds of entities are arranged in a hierarchy where human beings represent the higher order and natural physical things are located in the lower position. The items in the hierarchy are organised as follows:

\section{Human beings $>$ animals $>$ plants $>$ complex objects $>$ natural physical things}

From this basis, the Great Chain determines the relationships holding between the different orders of the hierarchy. Hence, each level is characterised by having the properties that define the lower ones but also incorporates an additional distinctive characteristic. In fact, 
by means of this metaphor, we are able to understand human attributes in terms of corresponding animal attributes, as in He is a fox, Mary is a snake, Peter is a whale. All these sentences are realisations of the PEOPLE ARE ANIMALS METAPHOR. In them, a culturally attributed behavioural feature of foxes (i.e. guile), snakes (i.e. malice), and whales (i.e. weight) is used to describe people. In this respect, Ruiz de Mendoza (1997) has argued that metaphors based on the Great Chain are invariably cases of one-correspondence metaphor. Therefore, in this sort of metaphor a singular aspect of the source domain is singled out and mapped onto the target domain. For instance, in Mary is a snake, the malice and spite typically associated with snakes (adders especially) is used to describe Mary's behaviour. This ontological metaphor makes it possible to highlight a quintessential feature of the source domain.

Nonetheless, this is not the exact way in which this ad works. In fact, the distinctive traits of the dog are made irrelevant since it is wearing shoes, which are not a culturally attributed feature. It is the combined image of the dumb dog wearing shoes the one that is mapped onto a person who consumes drugs. Thus, this advert makes us realise that drugs are as unnecessary for humans as shoes are for dogs.

\section{BEING UNPROTECTED IS BEING NAKED}

A Spanish campaign against drugs showed adult people in diapers taking drugs while enjoying a party. The slogan was Frente a las drogas estás en pañales (Eng. 'Playing with drugs, you're in diapers'). In this case, the diapers do not only prompt a metonymy that stands for the early childhood in which kids are somehow unprotected and highly vulnerable because they are unable to see the possible consequences of their actions (in the same way as adults who consume drugs are also 'blind'), but also they lead to the interpretation that the characters do not have clothes covering their bodies. Since the absence of clothes on one's body (being naked) is also a metaphor for being unprotected, the advertisement conveys the idea that when people take drugs there is no way in which they may be protected from their devastating effects, and that they will be unable to have control over the consequences. More sentences that prove the existence of this metaphor, which could be labelled BEING UNPROTECTED IS BEING NAKED, can be found in sentences like the ones below,

-Once you realize you are naked before the law and all this righteous rhetoric was only that, rhetoric, you are ready for most any deal the prosecutor throws at...

-Though I am fully clothed, you intimidate me. So much, I feel like a child, helpless, and unprotected.

-Comanche came out of the southern Rockies after generations of isolation. We were naked before the world.

\section{FAMILY IS A BOUNDED REGION WHICH GIVES PROTECTION}

As is the case with any kind of authority, many kids see that PARENTAL AUTHORITY AS A BOUNDED REGION, a metaphor which may find its experiential basis in the fact that many parents usually set barriers on the freedom of their children in such a way that 
they feel constrained. This metaphor can be considered a primary metaphor since by the time we are small kids, parents and educators normally tell us what we can do and what we cannot do, the rules thus being conceptualised as physical boundaries to our actions and movements. Everyday language also shows this metaphor that maps a bounded region onto any sort of authority,

-There is everything within my authority. We do not want any more choice.

-The parents in my area are happy with the choices they have.

-Only he would dare to go beyond my authority!

-Supreme Board of the Press Council has the power of taking any decision which does not trespass the authority of the members' council.

-In Iceland, at least, the Norwegians really did escape from the authority of rulers.

-She remains under the authority of her father's until she enters the authority of her husband, in marriage.

Nevertheless, in a more positive way, we may also conceive that the family is a sort of bounded region that gives protection. For instance, in many adverts related to cars, implying security aimed at small children, we normally see a father embracing his son thus creating a sort of protective bounded region which surrounds the child. Similarly, the bonds of love that make a family a solid unit create a sort of area of protection for its members in different aspects (love, care, finances, support, etc.). As related to drug consumption, families are also regarded as a sort of bounded region which offers support and protection against drugs. So, in the first advertisement we see a father with his smiling child on his back, and a slogan trying to encourage this family protection "Did you know your kid's drink can be spiked with ecstasy?" And, in the second, even though at first sight we get the impression of being looking at caring compact families which form a sort of WALL against drugs, if we read through the whole text that is not the idea conveyed at all. On the contrary, the families are there to represent people with different backgrounds and features (teens, seniors, addicts, poor, middle class people, etc.), who may have been arrested for taking or dealing with drugs, obviously being behind the wall, a metaphor for prison.

\section{- DRUG SWEEP}

This poster was especially aimed at drug dealers when some members of the air force joined the police in the fight against drugs in the USA. As we see, there is a pilot cleaning his fighter with a sort of broom. This image is there in order to support the slogan "drug sweep," since the term sweep means "To clean or clear, as of dirt, with or as if with a broom or brush: sweep a chimney". (Source: www dictionary .com). In order to interpret the message that underlies the poster, we obviously map the cleaning of drugs with a broom onto the arrest of drug dealers and people taking drugs in such a way that society becomes cleaner.

\section{- BALANCE IS A PAIR OF SCALES}

The image of a pair of scales usually represents a state of balance since this state is basically 
characterised by stability or rest due to the equal action of opposing forces. Even the star sign of Libra and the symbols deployed in courts around the world make use of the pair of scales to convey the idea of fair justice, especially in the case of courts where everybody is supposed to be treated and judged with equal rights. This sense of equality is related to the idea that everybody would "weigh the same" before the law regardless of his race, language, ethnic origin, etc.

Besides, the notion of balance has been seen as a image-schema by Johnson (1987), who regards the abstract notion of balance as a spatial construct with the category of an image schema. Image-schemas have been described as pre-conceptual topological abstractions (Johnson, 1987; Lakoff, 1987, 1989; Gibbs and Colston, 1995) that recurrently provide structured understanding of various experiences, thus being available for metaphorical use as a source domain to provide an understanding of yet other experiences. For instance, a compulsion schema is used to provide an understanding of experiences such as a jet airplane, geological forces moving continental plates, and metaphorically, the experience of peer pressure. From this viewpoint, the advert under analysis clearly makes use not only of the aforementioned metaphor but also of this schema in the slogan "Guidelines to rational drug use". Finally, in terms of Alfaro (2003), the slogan can be seen under the light of a static balance schema (as opposed to a dynamic one which could be applicable to arguments, for instance) since we are dealing with psychological balance and rationality.

\section{- EFFECT FOR CAUSE METONYMY}

This interesting poster plays both with images and words in order to convey the idea contained in the slogan "Drugs can be deadly". Obviously, the connection between taking drugs and death is highlighted by the image of the skeleton. This is achieved by means of two linked EFFECT FOR CAUSE metonymies which could be diagrammed as follows,

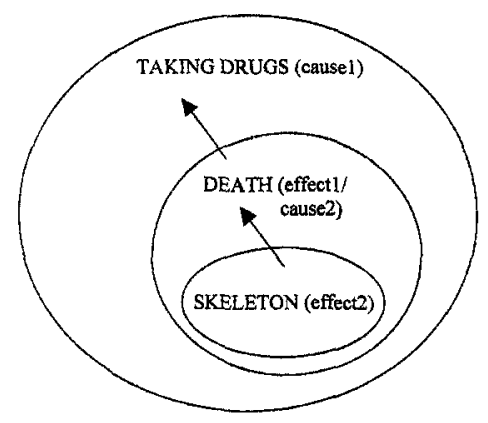

Figure 13. Skeleton for death for taking drugs.

As we see, taking drugs is a cause of death, and a skeleton is a clear effect of death, even though many people may think of it as a metaphor of death perhaps motivated by the well-known metaphor DEATH IS A GRIM REAPER (cf. Lakoff \& Turner, 1989; 
Fauconnier \& Turner, 1994, 1995, 1998), which is normally represented by means of a skeleton carrying a scythe. Moreover, the contextual effects of the advert that may be retrieved by the speaker further emphasise drug consumption as the main negative thing since, from a linguistics viewpoint, cause takes cognitive precedence over effect, in terms of saliency (Langacker, 1993). Finally, as Ruiz de Mendoza and Otal (2002) have shown, the EFFECT FOR CAUSE metonymy belongs to the source-in-target kind.

The inverted metonymy may be found in the poster which shows a man as if he were in prison, the syringes standing for the jail bars. It can be explained by means of a CAUSE FOR EFFECT METONYMY: taking drugs is the cause of being imprisoned. Besides, as we have mentioned before, since as regards saliency cause takes cognitive precedence over effect (Langacker, 1993), the syringes (standing for drugs) appear on the first level regarding depth. This target-in-source metonymy can be diagrammed as follows,

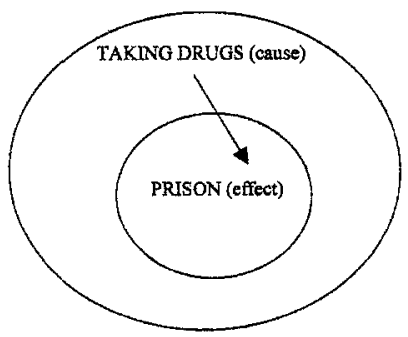

Figure 14. Taking drugs for being in prison.

\section{- "IF YOU PLAY WITH DRUGS, DON'T LOSE THE GAME"}

This poster issued by the Spanish trade union UGT must be interpreted on the basis of the metaphor LIFE IS A GAME. The slogan Si juegas con drogas, no pierdas la partida ('if you play with drugs, don't lose the game') contains a source space related to games which is mapped onto the target, which is in turn based on life. In order to interpret the slogan, we should focus on the correspondence related to (supportive) instruments, since drugs are normally used with that aim in mind. Besides, there is also a play upon words since "play with" is also connected to the idea of "messing up with". Hence, the interpreter links "play with" to the idea of "playing with something dangerous". The metaphor can be diagrammed as follows:

\begin{tabular}{|l|l|}
\multicolumn{1}{c|}{$\begin{array}{c}\text { SOURCE } \\
\text { game }\end{array}$} & \multicolumn{1}{c|}{$\begin{array}{c}\text { TARGET } \\
\text { life }\end{array}$} \\
\hline playing & developing \\
\hline instruments & supportive instruments \\
\hline rules & norms \\
\hline aims & goals \\
\hline lose/win & attain/not to attain \\
\hline
\end{tabular}

Figure 15. The LIFE IS A GAME metaphor. 


\section{-"WITH DRUGS YOU ARE DIGGING YOUR OWN GRAVE SOLIDLY"}

Even though this sentence appeared on a religious web page ${ }^{7}$ and not on a poster or advertisement as such, we make use of it as it is based upon an interesting blending with deserves some commentary. The sentence contains a source space (based upon "digging one's grave") which is mapped onto the target (based on "taking drugs"). Then, the generic space is created to control the mapping process, as it is the result of a mental operation of abstraction from the input spaces. Finally, the blended space is created as the mental space where the language user interprets the information. The whole process, which has already been discussed in Coulson (1997), Fauconnier \& Turner (1998), and Ruiz de Mendoza (1998) may be illustrated by means of the diagram on the following page.

\section{- "HE BURIED HIMSELF IN ALCOHOL"}

To end with, we make use of a sentence ("He buried himself in alcohol") that appeared on a literary webpage ${ }^{8}$ and which can also be explained by means of conceptual blending. The expression "to bury oneself in something" is a very productive pattern in English which means that a person devotes so much of his life immersed in a certain task that he seems to be dead. Some examples containing this pattern are:

(a) He buried himself in the life and the arts of the sea.

(b) As an expression of his protest and opposition, he buried himself in music, in translating Russian poetry, and in drawing and sculpting. As an expression of his protest and opposition, he buried himself in music, in translating Russian poetry, and in drawing and sculpting.

(c) To refute the teachings of the economists, they buried themselves in old documents and compiled numerous volumes dealing with the history of the administration.

\begin{tabular}{|c|c|c|}
\hline $\begin{array}{c}\text { SOURCE } \\
\text { (Input space 1) }\end{array}$ & $\begin{array}{l}\text { GENERIC } \\
\text { SPACE }\end{array}$ & $\begin{array}{c}\text { TARGET } \\
\text { (Input space 2) }\end{array}$ \\
\hline Someone digs a grave. & Someone does a specific action. & $\begin{array}{l}\text { Someone is doing harm to } \\
\text { himself. }\end{array}$ \\
\hline $\begin{array}{l}\text { A shovel is used as the digging } \\
\text { instrument. }\end{array}$ & There is an instrument used. & Drugs are taken. \\
\hline $\begin{array}{l}\text { The grave is going to be for a } \\
\text { dead person in a near future. }\end{array}$ & The action is related to death. & $\begin{array}{l}\text { By means of doing continuous } \\
\text { harm to oneself, one may die. }\end{array}$ \\
\hline $\begin{array}{l}\text { The dead person is the digger } \\
\text { himself. }\end{array}$ & The doer of the action dies. & $\begin{array}{l}\text { The one who was doing harm to } \\
\text { himself dies. }\end{array}$ \\
\hline $\begin{array}{l}\text { The digger has the possibility to } \\
\text { stop digging with the shovel so } \\
\text { that he doesn }{ }^{4} \text { die. }\end{array}$ & $\begin{array}{l}\text { The doer may prevent death by } \\
\text { stopping the action. }\end{array}$ & $\begin{array}{l}\text { The drug consumer may stop } \\
\text { taking drugs in order to avoid } \\
\text { death. }\end{array}$ \\
\hline
\end{tabular}

BLENDED SPACE

Someone repeatedly takes drugs and that is killing him. The drug consumer is still in time to avoid death by leaving drugs.

Figure 16. "With drugs you are digging your own grave solidly".

Finally, we can account for this expression by means of the following diagram, 


\begin{tabular}{|c|c|c|}
\hline $\begin{array}{c}\text { SOURCE } \\
\text { (Input space 1) }\end{array}$ & $\begin{array}{l}\text { GENERIC } \\
\text { SPACE }\end{array}$ & $\begin{array}{l}\text { TARGET } \\
\text { (Input space 2) }\end{array}$ \\
\hline $\begin{array}{l}\text { Someone buries a dead person } \\
\text { in a tomb. }\end{array}$ & Someone does a specific action. & $\begin{array}{l}\text { Someone devotes so much time } \\
\text { of his life to drink alcohol that } \\
\text { he does not seem to be alive. }\end{array}$ \\
\hline $\begin{array}{l}\text { Sand covers the tomb and } \\
\text { surrounds the dead person } \\
\text { completely. }\end{array}$ & $\begin{array}{l}\text { Covering and surrounding } \\
\text { element. }\end{array}$ & $\begin{array}{l}\text { Alcohol is surrounding the } \\
\text { whole life of that person, as if } \\
\text { he were encapsulated by it. }\end{array}$ \\
\hline $\begin{array}{l}\text { In order to come back to life, } \\
\text { the dead person should leave } \\
\text { the tomb and the surrounding } \\
\text { sand. }\end{array}$ & Someone leaves a close place. & $\begin{array}{l}\text { In order not to devote so much } \\
\text { time to drink, he should give up } \\
\text { alcohol. }\end{array}$ \\
\hline
\end{tabular}

BLENDED SPACE

Someone devotes so much time of his life to drink alcohol that he seems to be dead in a tomb surrounded by alcohol.

Figure 17. "He buried himself in alcohol".

\section{Conclusion}

Whereas previous approaches to advertising have focused on how adverts work within the framework of general communication, with the exception of Coulson (2000) who deeply analysed the role of blending in meaning derivation, in this paper we have carried out a systematic analysis of the advertisements under study in order to show in detail how not only conceptual blending but also metaphor and metonymy have a crucial role in deriving the central implicature of the advert. More specifically, we can posit that the receivers of the analysed adverts, on the basis of the advert basic elements (such as images, characters and their features or behaviours, slogans, etc.), automatically generate a mental process whereby they reach the central message the adverts have been designed to convey. Strikingly enough, metaphor, metonymy, and conceptual blending lie at the basis of this mental process which, in terms of relevance (c.f. Sperber and Wilson, 1993, 1995) tries to achieve the greatest cognitive effect using the least cognitive effort. This is the reason why advertisements of this kind express so much by saying so little; actually, the fact that such advertisements are generally extremely shocking may be explained on the basis of the gradually growing inferences the receivers develop within their minds, and which are ultimately determined by the mappings under scrutiny.

In essence, besides confirming that conceptual interaction is fully regulated and constrained by a limited set of interactional patterns, we have provided additional evidence in support of the thesis that conceptual metaphor, metonymy, and blending play a crucial role in the correct interpretation of advertisements since they lead the receiver to the main inference the advert tries to convey. Furthermore, we have also shown that, in addition to determining the semantics of the slogans and adverts in general, the underlying mappings also constrain the choice of their related visual layouts in terms of characters and their traits, proxemics, kinesics, and other elements that determine the overall multimodality of 
the texts. In this respect, the overall communicative effects brought about by the advertisement are further reinforced.

\section{Notes}

1. Part of a talk delivered at AESLA Annual Conference, 2004. Financial support for this research has been provided by the DGI, Spanish Ministry of Education and Science, grant no. HUM2004-05947-C02-01/FILO. The research has been co-financed through FEDER funds.

2. According to Richards et al. (1992: 262), "the study or use of non-vocal phenomena such as facial expressions, head or eye movements, and gestures which may add support, emphasis, or particular shades of meaning to what people are saying $(\ldots)$ ".

3. In terms of Richards et al. (1992: 299), "the study of the physical distance between people when they are talking to each other, as well as their postures and whether or not there is physical contact during their conversation (...)".

4. Some examples have been critically reviewed in Ruiz de Mendoza (1998a, 1998b, Ruiz de Mendoza \& Díez 2002). Even a new model has been posited by Ruiz de Mendoza \& Díez (2002) under the name of "Combined Input Hypothesis".

5-6. Note how in both cases the events are left behind the speaker.

7. http://www.resurrectionpower.com/page 718.htm.

8. http://www.theromancestudio.com/reviews/reviews/wildhoneyquinn.htm.

\section{References}

Alfaro, Nuria (2003): "Some notes on the balance image-schema". Talk at the $8^{\text {th }} I C L C$. Logroño: Universidad de La Rioja.

Brierley, Sean (1995): The Advertising Handbook. London: Routledge.

Coulson, Seana (2000): Semantic Leaps: Frame-shifting and Conceptual Blending in Meaning Construction. Cambridge: Cambridge University Press.

Coulson, Seana and Todd Oakley (2000): "Blending Basics". Cognitive Linguistics 11-3/4 183 (2001): "Metonymy and conceptual blending". Internet document.

[http://cogsci.ucsd. edu/-coulson/metonymy-new.htm].

Fauconnier, Gilles and Mark Turner (1994): "Conceptual projection and middle spaces". UCSD Department of Cognitive Science Technical Report 9401.

(1995): "Conceptual integration and formal expression". Metaphor and Symbolic Activity 10: 183-204.

. (1996): "Blending as a central process of grammar". In A, Goldberg, ed., Conceptual

Structure, Discourse and Language. Stanford: CSLI Publications, 113-130.

. (1998): "Conceptual integration networks". Cognitive Science 22 (2): 133-187. (2000): "Compression and global insight". Cognitive Linguistics 11(3-4): 283-304. (2001): "Conceptual integration networks" (expanded version).

[www.mform.umd.edu/EdRes/Colleges/ARHU/Depts/English/engfac/Mturner/cin. Web]. . (2002): "Metaphor, metonymy, and binding". In R. Dirven and R. Pörings, eds., Metaphor and Metonymy in Comparison and Contrast. Berlin/ New York: Mouton de Gruyter, 469-488. 
Gibbs, Raymond and Herbert Colston (1995): "The cognitive psychological reality of image schemas and their transformations". Cognitive Linguistics 6(4): 347-378.

Goossens, Louis. (2002): "Metaphtonymy: the interaction of metaphor and metonymy in expressions for linguistics action". In R. Dirven and R. Pörings, eds., Metaphor and Metonymy in Comparison and Contrast. Berlin/ New York: Mouton de Gruyter, 349-378.

Grady, Joseph, Todd Oakley and Seana Coulson (1999): "Blending and metaphor". In R. Gibbs and G. Steen, eds., Metaphor in Cognitive Linguistics. Philadelphia: John Benjamins, 101-124.

Herrero, Javier (2002): "The emeralds of your face': Metaphor and metonymy in some eye expressions".

Herrero, Javier (2002): "Sequencing and integration in metaphor-metonymy interaction". RESLA 15: 73-91.

Johnson, Mark (1987): The Body in the Mind: the Bodily Basis of Meaning, Imagination and Reason. Chicago: University of Chicago Press.

345-366.

Lakoff, George (1987): Women, Fire, and Dangerous Things: What Categories Reveal About the Mind. Chicago: University of Chicago Press.

. (1989): "Some empirical results about the nature of concepts". Mind \& Language 4(12): 103-129.

. (1990): "The invariance hypothesis: Is abstract reasoning based on image-schemas?" Cognitive Linguistics 1(1): 39-74.

. (1993): "The contemporary theory of metaphor". In A. Ortony, ed., Metaphor and Thought, $2^{\text {nd }}$. ed. Cambridge: Cambridge University Press, 202-251.

Lakoff, George and Mark Johnson (1980): Metaphors We Live By. Chicago: The University of Chicago Press.

. (1999): Philosophy in the Flesh. The Embodied Mind and Its Challenge to Western Thought. New York: Basic Books.

Lakoff, George and Mark Turner (1989): More Than Cool Reason. A Field Guide to Poetic Metaphor. Chicago: The University of Chicago Press.

Langacker, Ronald W. (1987): Foundations of cognitive Grammar, vol. 1. Theoretical Prerequisites. Stanford: Stanford University Press.

(1990): Concept, Image and Symbol: The cognitive basis of Grammar. Berlin: Mouton de Gruyter.

. (1991): "8. Cognitive Grammar". In Droste, F.G. and J.E. Joseph, eds., Linguistic Theory and Grammatical Description, $275 \mathrm{ff}$.

. (1993): "Reference-point constructions". Cognitive Linguistics 4-1; 1-38.

Myers, Greg (1994): Words in Ads. London: Edward Arnold.

Otal, José L. and Francisco J. Ruiz de Mendoza (2002): Metonymy, Grammar, and Communication. Granada: Comares.

Pérez, Lorena and Francisco J. Ruiz de Mendoza (2001): "Metonymy and grammar: Motivation, constraints and interaction". Language and Communication 21(4): 321-357.

Rein, David (1982): The role of Language in Advertising and Merchandising. London: Routledge.

Richards, Jack C., Platt, John, and Heidi Platt (1992): Dictionary of Language Teaching and Applied Linguistics. Plantin: Longman. 
Ruiz de Mendoza, Francisco J (1997a): "Metaphor, metonymy and conceptual Interaction". Atlantis 19(1): 281-295.

. (1997b): "Cognitive and pragmatic aspects of metonymy". Cuadernos de Filologia Inglesa 6(2): 161-178.

. (1998a): "Blended spaces and the pragmatic approach to cognition." In B. Penas, ed., The Intertextual Dimension of Discourse. Universidad de Zaragoza: Servicio de Publicaciones, 233-244

. (1998b): "On the nature of blending as a cognitive phenomenon." Journal of Pragmatics 30(3): 259-274.

. (1999a): Introducción a la teoría cognitiva de la metonimia. Granada: Método Ediciones.

. (1999b): "From semantic underdetermination via metaphor and metonymy to conceptual interaction". LAUD 492. Essen.

. (2000): "The role of mappings and domains in understanding metonymy". In A.

Barcelona, ed., Metaphor and Metonymy at the Crossroads. A Cognitive Perspective. Berlin/ New York: Mouton de Gruyter, 109-132.

Ruiz de Mendoza, Francisco J. and Lorena Pérez (2001): "Metonymy and the grammar: motivation, constraints and interaction". Language \& Communication 21(4): 321- 357.

Ruiz de Mendoza, Francisco J. and Olga Díez (2002): "Patterns of conceptual interaction". In

Rene Dirven and Ralf Pörings, Metaphor and Metonymy in Comparison and Contrast. Berlin/

New York: Mouton de Gruyter; 489-532.

Sánchez, Jesús M. and Patricia Gómez (2002): "What is going on in an advert?. The role of cognitive tools in the construction of persuasive message". Talk at the AESLA Annual Conference, 2002. Universidad de Jaén.

Sperber, Dan and Deirdre Wilson (1993): "Linguistic form and relevance". Lingua 90: 1-25. (1995): Relevance. Communication and Cognition. Oxford: Basil Blackwell.

Sweetser, Eve and Rafael Núñez (2001): "Spatial embodiment of temporal metaphors in Aymara: Blending source-domain gesture with speech. "Talk at the 7th ICLC. University of California, Santa Barbara.

Tanaka, Keiko (1994): Advertising Language: A Pragmatic Approach to Advertisements. London: Routledge. 

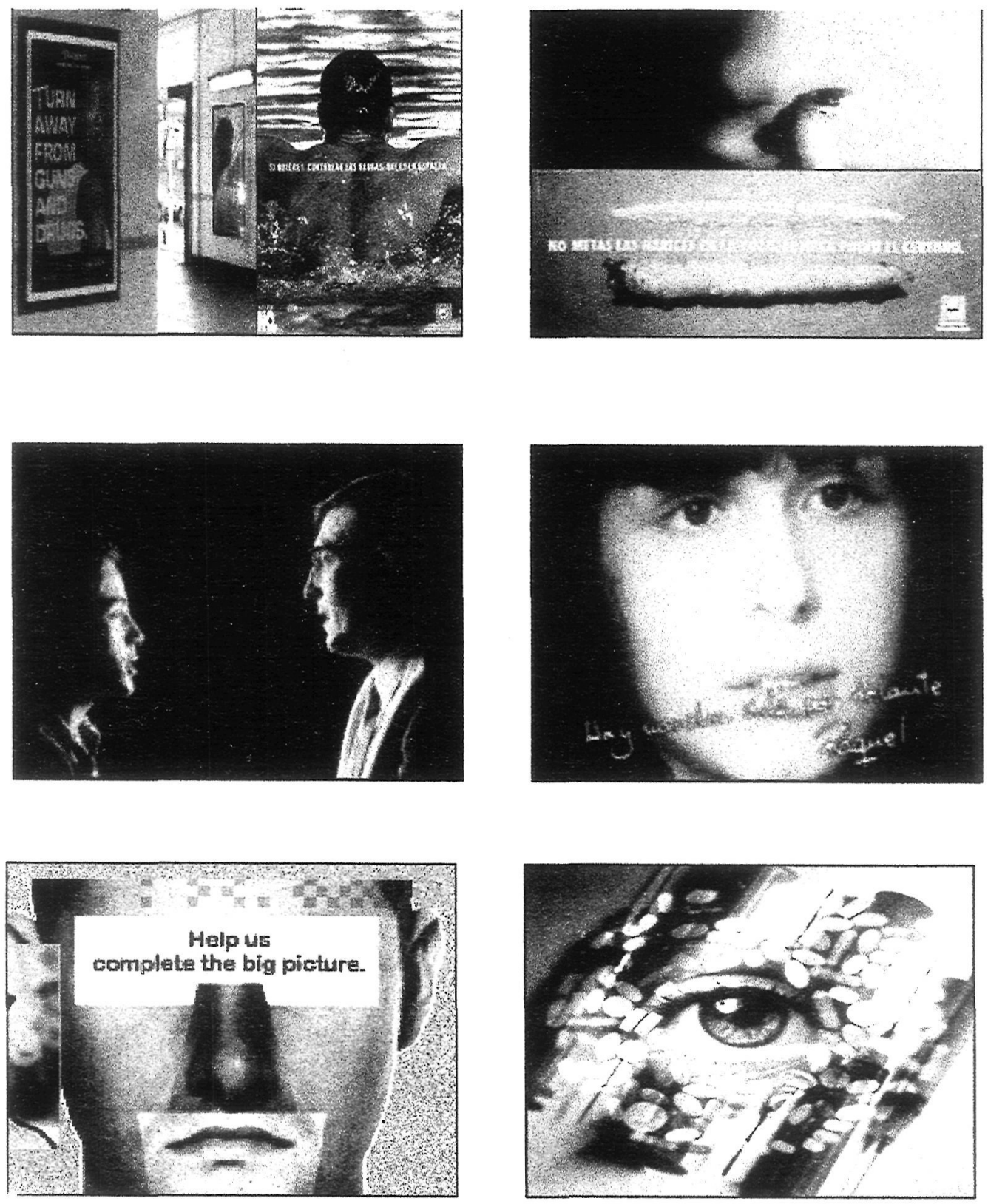

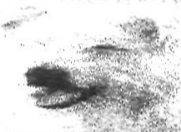

TAKUME DRUGS IS UUST AS DUME.

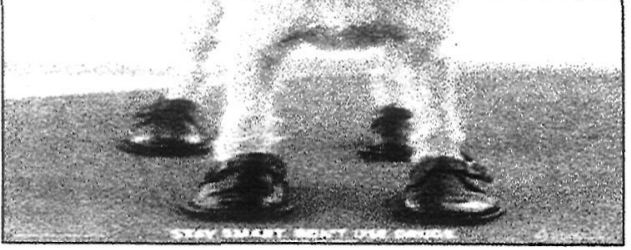

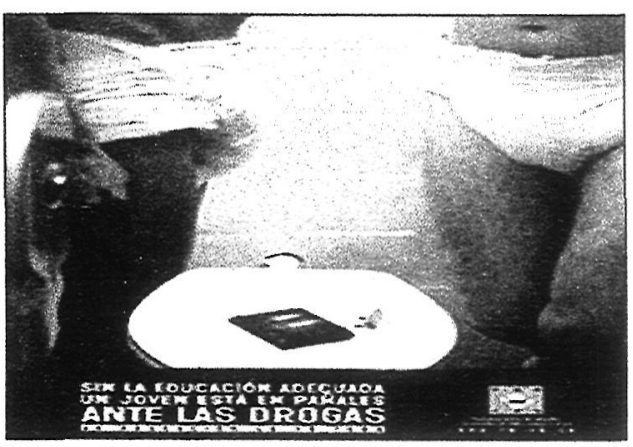



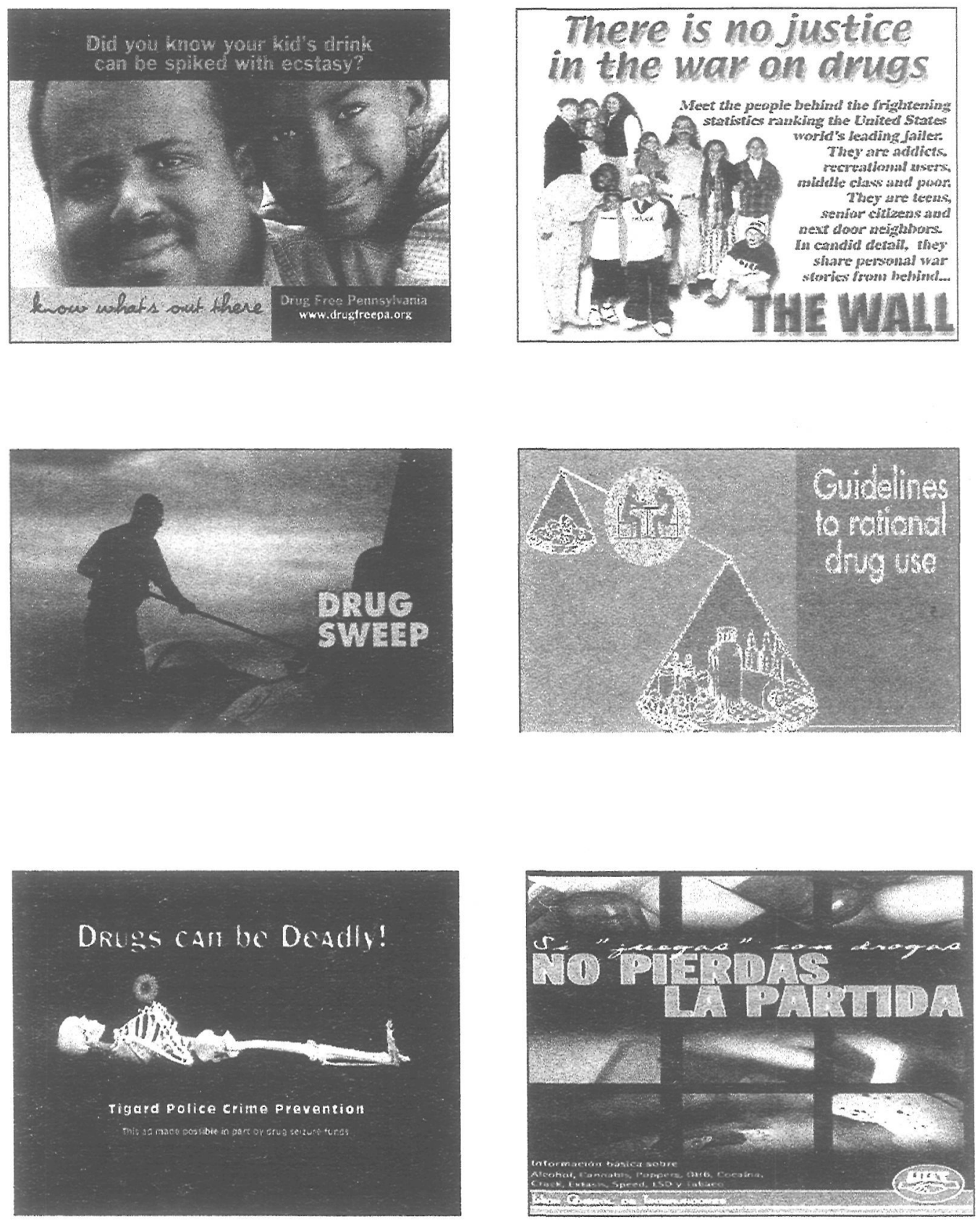

Note: these images have been obtained from www.google.es. Many thanks to the National Museum of the U.S. Air Force, The November Coalition (http://www.november.org), Fundación de Ayuda contra la Drogadicción (www.fad.es), UGT (www.ugt.es), Drug Free Pennsylvania, MacMillan Education, Tigard and London Police. 